\title{
Comparison Between The Efficient Of Routing Protocol In Flying Ad-Hoc Networks (FANET)
}

\author{
Hadeel M. Taher Alnuami \\ University of Anbar- Iraq. \\ hadeilmt@yahoo.com \\ Recived : $28 \backslash 9 \backslash 2017$ \\ Revised : 12\10\2017 \\ Accepted : 29\11\2017
}

Available online : 24/1/2018

DOI: $10.29304 / j q c m .2018 .10 .1 .346$

\begin{abstract}
Flying Ad-Hoc Networks (FANETs) is a crowd of Unmanned Air Vehicles (UAVs). The role of the UAV is very developing speedily. Through the advancement of technologies various interesting tasks are likewise related like growth and maintenance cost and incorporation. This technology area is present, which are used for communication purpose. The main characteristics of FANET are flexible, low-cost besides fast to arrange or organize a network. On the other hand, there are the main problems in this category of networks that is the communication between any Unmanned Air Vehicles besides the random movement of UAV in this network. In this paper focused on the mean of FANET network and the main routing protocols on this modern area, then compare between two routing protocol AODV and DSR. The result led to AODV is better than DSR routing in three parameters: PDR, E2E delay and throughput. In addition AODV more appropriate for FANET environment than DSR with different number of nodes in the FANET network.
\end{abstract}

Keywords- MANET,VANET, FANET, Routing Protocol.

\section{Introduction}

In case of calamitous occurrence, when there are lucky in centre point that lead the service out or basically not available, for resolving these issues used a group of flying nodes that known as UAVs can provide a speedy deployable in addition selfmanaged ad hoc network [1]. As shown in figure (1) the flying ad hoc network (FANET) is a subset of ad hoc network like other ad hoc network such as (MANET) and (VANET) on the main features like wireless medium and random deployment but also the FANET have special characteristic to identification of FANET network [2]. FANET may include heterogeneous or

homogenous Unmanned air Vehicles (UAVs) that are capable to interconnect with each other in the area, besides interacts through their environments to obtain some kind of valuable information [1]. FANET do not usage, fundamental controlled scheme [3].

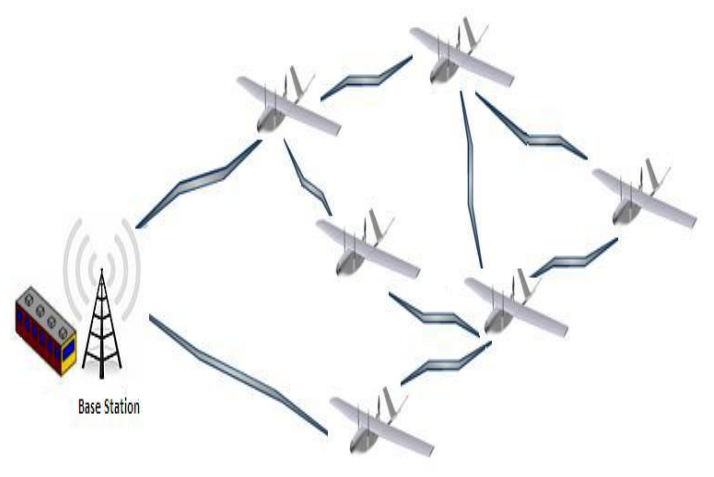

Fig.(1): Flying Ad hoc Network(FANET). 


\section{Wireless Ad Hoc Network}

Mobile Ad-hoc Network: MANET: are crowed of nodes that connected between them by wireless communication channel. In1970 "DARPA" the first concept form of MANET that depended on infrastructure less networks [4]. The nodes are free and random mobile in any deployment changes repeatedly. There are many challenging issues in mobile ad-hoc networks such as power control, security delay sensitivity [3]. As shown in figure (2).

\section{Fig.(2): Mobile Ad hoc Network (MANET).}

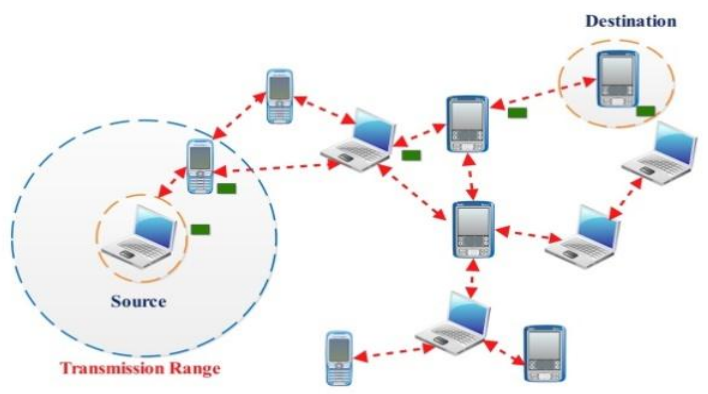

Vehicular Ad-hoc Network: VANET: is subsection from MANET, each node in VANET called Vehicular on the road (network)[5]. It related with MANET in many features, but also different in other features. The VANET used today's because there are many biggest problems in traffic management [6]. VANET achieved two methods of communication: the first on depended on fixed infrastructure and vehicle node. Another method chastely wireless infrastructureless networks [7]. Vehicular ad- hoc network has numerous application such as: Safety applications (Collision avoidance, Traffic Management and Co-operative driving) and User applications (Electronic toll collection, Entertainment Applications, Internet Access and Locating fuel station) [5]. As shwn in figure (3).

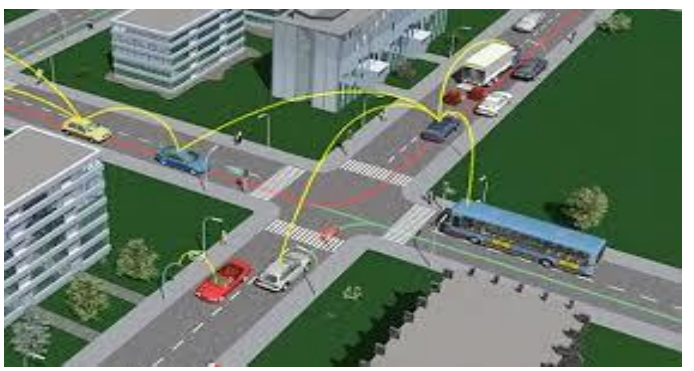

Fig.(3):Vehicular Ad hoc Network(FANET).
Flying Ad hoc Network: FANET is a subclassification of vehicular ad hoc network. That means the biggest network MANET then VANET after that the FANET came [4]. Because VANET and FANET have the main feature of MANET with some of the differences. The node in FANET called Unmanned Aerial Vehicles(UAV)[8]. Each node in fly network can fly autonomously with no pilot on it, it operated by programmed flight plans or by dynamic automation systems [9]. FANET are infrastructureless networks with no central point. This network has many applications such as location aware services, rescue operations and security services [10]. As shown in table (1) that explain the main difference between types of $\mathrm{Ad}$ hoc network.

\section{Table(1):Comparison between Ad-Hoc Networks}

\begin{tabular}{|c|c|c|c|}
\hline \multicolumn{4}{|c|}{ AD HOC NETWORK TYPES } \\
\hline FANET & MANET & \multicolumn{2}{|c|}{ VANET } \\
\hline $\begin{array}{c}\text { Node called } \\
\text { Unmanned } \\
\text { Aerial } \\
\text { Vehicle } \\
\text { (UAV) } \\
\end{array}$ & $\begin{array}{l}\text { Node called } \\
\text { mobile node }\end{array}$ & \multicolumn{2}{|c|}{ Node called Vehicle node } \\
\hline $\begin{array}{c}\text { High } \\
\text { Movement }\end{array}$ & $\begin{array}{c}\text { Low } \\
\text { Movement }\end{array}$ & \multicolumn{2}{|c|}{ Moderate Movement } \\
\hline \multicolumn{2}{|c|}{$\begin{array}{l}\text { Very large of nodes } \\
\text { consume energy }\end{array}$} & $\begin{array}{l}\text { Limited of } \\
\text { nodes } \\
\text { consume } \\
\text { energy }\end{array}$ & $\begin{array}{l}\text { Limited of } \\
\text { nodes } \\
\text { consume } \\
\text { energy }\end{array}$ \\
\hline \multicolumn{2}{|c|}{ Rapid deployment } & $\begin{array}{c}\text { Slow } \\
\text { deployment }\end{array}$ & $\begin{array}{c}\text { Rapid } \\
\text { deployment }\end{array}$ \\
\hline \multicolumn{2}{|c|}{$\begin{array}{l}\text { Geospatial localization } \\
\text { (GPS, AGPS) }\end{array}$} & $\begin{array}{c}\text { Geospatial } \\
\text { localization } \\
\text { (GPS) }\end{array}$ & $\begin{array}{c}\text { Geospatial } \\
\text { localization } \\
\text { (GPS, } \\
\text { AGPS) }\end{array}$ \\
\hline \multicolumn{2}{|c|}{$\begin{array}{c}\text { Lower than MANET } \\
\text { node density }\end{array}$} & $\begin{array}{l}\text { Low node } \\
\text { density }\end{array}$ & $\begin{array}{l}\text { Higher } \\
\text { node } \\
\text { density }\end{array}$ \\
\hline
\end{tabular}




\section{Unmanned Aerial Vehicle (UAV)}

FANET have a group of UAV that distinguish as the size is small with fast deployment in addition the flexibility of nodes [11]. The UAV as a team when mobile according to trajectories defined through separable responsibilities that should be allocated to perform a comprehensive mission. There are two types of UAV: The first one called single-UAV or small UAV system that depended on a star deployment network that make UAV is a focus point [5]. An earth node may indirectly interconnect through others over the UAV. The main problem in this topology if the main point (focus point) fails all the system the UAV has to come back to the base [2]. On the other hand, this system has many advantages such as lower cost and speedily than the second type of UAV [3]. Conversely, in multi-UAV systems, the speed low than single system and more cost, but rather than the UAVs can share responsibilities amongst themselves besides this increases the fault tolerance of the UAV system. As the first type, this system also has advantages such as the dynamic topology of the network, but the communication among UVAs in FANETs it's still problematic [7]. This problem will be solved by using two protocols one between UAV and the central point and the second used between the UAVs itself [12]. As shown in table (2) that explain the main difference.

Table (2): The main difference between MultiUAV System and Small UAV System

\begin{tabular}{|c|c|c|}
\hline \multicolumn{3}{|c|}{ UAV Type of FANET } \\
\hline Feature & $\begin{array}{c}\text { Multi-UAV } \\
\text { System }\end{array}$ & $\begin{array}{c}\text { Small UAV } \\
\text { System }\end{array}$ \\
\hline Cost & Large cost & $\begin{array}{c}\text { Lower cost } \\
\text { than Multi- } \\
\text { UAV }\end{array}$ \\
\hline Scalability & Easy & Limited \\
\hline Speed & High & Low \\
\hline $\begin{array}{c}\text { Small radar } \\
\text { cross- } \\
\text { section: }\end{array}$ & $\begin{array}{c}\text { Very small radar } \\
\text { cross- } \\
\text { sections(more } \\
\text { than one) }\end{array}$ & $\begin{array}{c}\text { Usually one } \\
\text { large radar } \\
\text { cross-section }\end{array}$ \\
\hline $\begin{array}{c}\text { Survivabilit } \\
\text { y }\end{array}$ & $\begin{array}{c}\text { Better than if one } \\
\text { UAV failed the } \\
\text { other UAVs will } \\
\text { survive the } \\
\text { system. }\end{array}$ & $\begin{array}{c}\text { Multi-UAV } \\
\text { System }\end{array}$ \\
\hline
\end{tabular}

\section{Routing Protocols On FANET}

Routing in FANET as well as MANET and VANET network must be classified by four main modules as in figure (4):

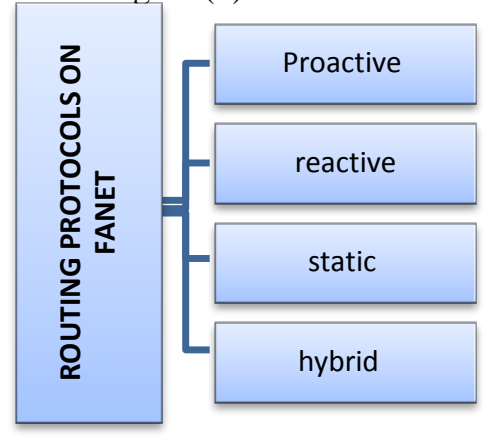

Fig(4):FANET routing protocol.

- Proactive routing protocol depended on routing table that are from time to time refreshed such as:

- Destination Sequenced Distance Vector (DSDV): This routing protocol must be all UAV in FANET network know everything about each other. The technique is different in the process than the main proactive approach because when used this protocol in FANET the sequence number assigned through the target node so as to remove the loop of routing happened via make alterations in the deployment of network [8].

- Directional Optimized Link State Routing (DOLSR): Any node in the FANET network must be know information about each other node. But this protocol has two messages, the first one control messages that used to know any different in deployment of FANET network[3]. The second one is hello message, which is sent from time to time to check the connect with neighbors in communication region. Multipoint Relay used in DOLSR when somewhat node requirements to transmission the data to other nodes, it will choice an MPR to frontward the routing messages [10]. 
- Reactive routing protocol usually discovers the route on demand only:

- Dynamic Source Routing (DSR): This routing protocol was applied through Brown et al. In [16]. This Routing based on multi-hop in FANET network. Any source node in FANET save the route to target node on the header of the data. To avoid any confectionary in FANET the UAV transfer the data with a request ID. Apply the DSR on FANET network it cannot be easy[7].

- Ad-hoc On-demand Distance Vector (AODV): AODV is one of famous protocol in reactive routing, the main feature of AODV that keeps one record for any node in the AODV table and AODV keeps only the path of the next hop which maximizes bandwidth in the FANET network. This routing based on three steps, the first one called the discovery process used to discover the route from the source to the target node and to avoid the loop. The second step, transferring the data, in the last step called routing maintaining that used to fix and refresh the routing tables [11].

- The third routing protocol is static that have a permanent routing table there is no refreshed with time:

- Load Carry and Deliver Routing (LCAD): LCDR is one of famous routing protocols in FANET network. The method of this protocol depended on transmission information by using flying UAV between two points in a ground. But this transmission must be happened with one hop[1]. The distance between these two point (begin and target) based on the UAV rapidity. On the other hand LCDR secure because only one hop between begin and target nodes[12].

- Multilevel Hierarchical Routing (MLH): This protocol based on UAVs clusters that mean the process of transfer data between the UAVs and a ground station. The cluster head separate operations between each cluster in specific ranges. This routing protocol useful when large network that is main different from load carry and delivering routing [9].

- Data-Centric Routing (DCR): This routing protocol based on one-to-many that led to communication between some data required by numerous UAVs in the FANET network. As the multilevel hierarchical routing the DCR clusters besides works as follows [6]. This DCR has weakness is the redundant data sent on FANET network. On the other side, the feature of the DCR is the message transfer procedure is not blocked among UAVs that called flow decoupling and the second feature is space decoupling the ID besides the location of the UAVs in FANET network. The last feature, there is no required to be UAVs online entirely time [8].
- The last one called hybrid routing protocol is a mixture between proactive in addition to reactive protocol: such as Zone Routing Protocol (ZRP),Temporarily Ordered Routing Algorithm (TORA)[5].

\section{Application scenario of FANET}

Flying Ad Hoc Network (FANET) with built-in sensors to reconnoiter $3 \mathrm{D}$ space, the UAV scheme requirement scan its location and react in real-time to regulate position and formation. Surveillance, search and saving tasks in misadventure recovery, and objective localization.

\section{Proposed Solution}

In this paper, we proposed system, routing protocols DSR and AODV are designated briefly besides the performance constraints of this protocol are also covered. This part shows how DSR, AODV protocols define mechanisms to their route strategy depended on the reactive category. This proposed system useful to decrease the connected cost in base location control besides efficiency of routing. Any node in FANET achieves protocols on the way to evaluate the performance, these protocols have dissimilar parameters such as delay, bandwidth and overhead. In this system the FANET will select the effective protocol on the way to broadcast the packet as shown in figure(5).

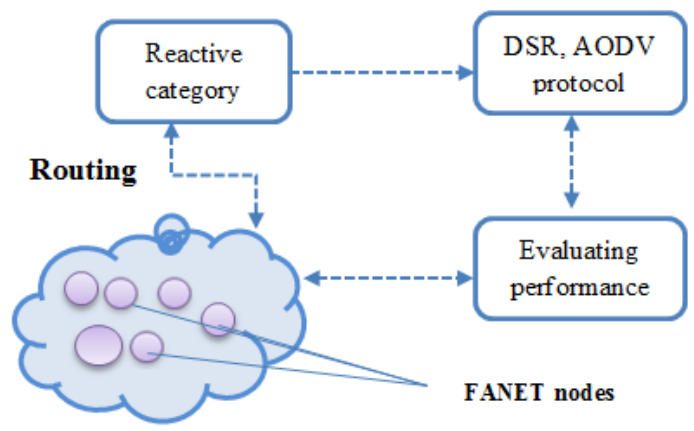

Fig(5):Architecture Diagram. 


\section{Simulation}

The NS2 simulator used for calculating, analysing and evaluating the effectiveness with the performance of AODV and DSR. The ns2 have types of connecting protocol such as: UDP, multicast routing and TCP. Also NS2 covered both main type of network like wired and wireless network. Ns2 depended on c++ as backend with $\mathrm{OTcI}$ interpreter.

However, these two protocols have different parameter with dissimilar in performance area as follow:

- Packet delivery ratio: it's the ratio of data packet receiving through the targets to those created by the source nodes. The equivalent used for the packet delivery ratio mathematically.

Packet delivery ratio $=$ Total of data packet receiving through the each target/ Total of data packets generated through the each source.

- End to End delay (E2E Delay): its depended on the time line. It takes the middling time of the data packets that consume to arrive the target node in FANET. Any delay may be occurs through the way between nodes to reach the target.

The average of the $\mathbf{E} 2 \mathbf{E}=$ Total of the time consumed to send packets for each target/ N.

- Throughput: Its defining the total number of successful data packet delivery above a Communication channel.

Throughput $=$ N/1000

Where $\mathrm{N}$ is the number of bits reached successfully through every target.

Table (3): Simulation Parameters

\begin{tabular}{|c|c|}
\hline \multicolumn{2}{|c|}{ NS2 } \\
\hline Parameter & Value \\
\hline Simulator & NS2 (Version-2.35) \\
\hline Protocols & AODV and DSR \\
\hline Channel Type & $\begin{array}{c}\text { Channel/Wireless } \\
\text { Channel }\end{array}$ \\
\hline Simulation duration & 150 s \\
\hline Traffic Type & CBR \\
\hline Data Payload & 512 Bytes / packet \\
\hline $\begin{array}{c}\text { Number of Nodes } \\
\text { per simulation }\end{array}$ & $50,100,200$ \\
\hline Node Speed & $\begin{array}{r}5,15,25 \text { (Meter/Sec) } \\
\text { Max of }\end{array}$ \\
\hline
\end{tabular}

\section{Analysis and Examination}

The result, as estimation shows the AODV routing is better than DSR routing protocol because the performance of the DSR is decreasing frequently whereas the packet delivery ratio is increasing in AODV. On the other hand the delay in AODV will be highest than DSR in FANET network. In throughput metric the AODV routing is effective at what time compared to DSR routing when apply on FANET environment as in figure (6),(7).

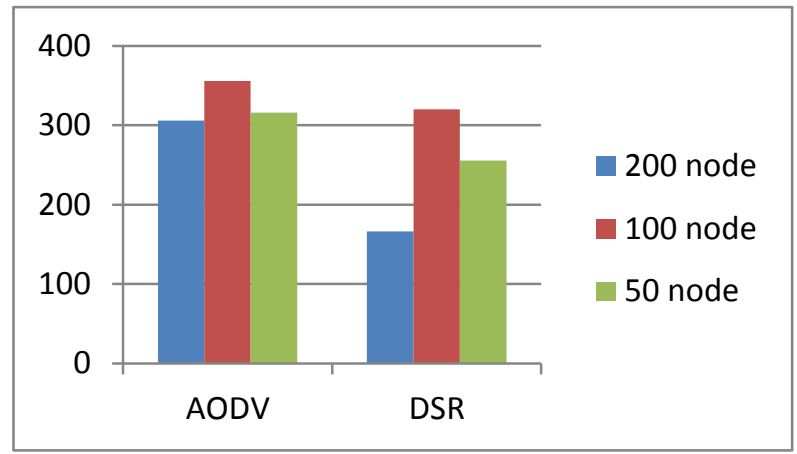

Fig(6): Throughput between AODV and DSR.

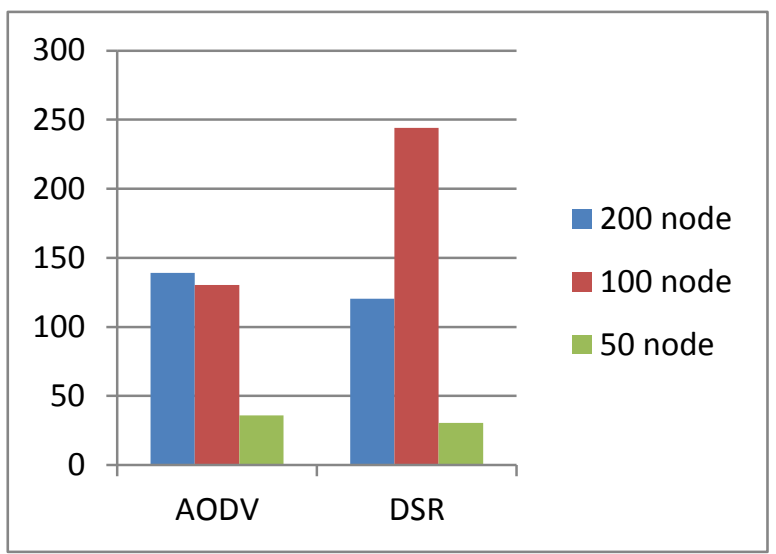

Fig(7). E2E delay between ADOV and DSR. 


\section{Conclusion}

The paper has a study to the new network called FANET its modern area developing fast, we compare between the main ad- hoc wireless network VANET, MANET and FANET. Furthermore, Mobility is the greatest interesting problematic for FANET network. On the other hand, in this research there are different parameter in different number of nodes with two types of routing protocol. The estimation result focus on the AODV routing is better than DSR routing on FANET network, because the first routing is flexible for the environment of the FANET and could be developing this protocol to be more suitable.

In future we could develop many ideas in this modern FANET area such as:

1- Merge between two routing protocols and apply these two routing on FANET network and made new routing just for FANET.

2- Apply the Decentralized Cloud Approach in FANET network.

3- Secure the path between UAVs and station to prevent any malicious node from reach to any data. This point important, specially in military application.

4- Optimize on the UAVs in FANET.

5- Calculate the packet drop in ADOV and DSR in FANET .

6- Approve the DSR and AODV routing used in FANET when distance is long of communication for coverage area.

\section{References}

1. K. Kumari, B. Sah and S. Maakar, "A Survey: Different Mobility Model for FANET", International Journal of Advanced Research in Computer Science and Software Engineering, 2015.

2. Naveen, S. Maakar, "Concept of Flying AD-Hoc Network: A Survey”, Proceedings of National Conference on Innovative Trends in Computer Science Engineering (ITCSE-2015) held at BRCMCET, Bahal on 4th April 2015.
3. M. Yassein and N.Damer, "Flying AdHoc Networks: Routing Protocols, Mobility Models,Issues",International Journal of Advanced Computer Science and Applications, Vol. 7, No. 6, 2016.

4. C. Barrado, R. Messeguer, J. López, E. Pastor, E. Santamaria and P. Royo, "Wildfire monitoring using a mixed airground mobile network", IEEE Pervasive Computing, 2010.

5. Singh et al,"A Comprehensive Survey on Fanet : Challenges and Advancements", International Journal of Computer Science and Information Technologies, 2015.

6. Md. Hasan, Md. Hossain and M. Atiquzzaman, "On the Routing in Flying Ad hoc Networks", IEEE Proceedings of the Federated Conference on Computer Science and Information Systems, 2015.

7. K. Kumari, S. Maakar and B. sah, "A Brief Survey of Mobility Model for FANET", National Conference on Innovative Trends in Computer Science Engineering held at BRCMCET4th ,April 2015.

8. Sudip, Misra and Gopidi Rajesh," Bird Flight- Inspired Routing Protocol for Mobile Ad Hoc Networks", ACM Transactions on Autonomous and Adaptive Systems, Vol. 6, No. 4, Article 25, October 2011 .

9. G. Heitz, D. Floreano and B. Rimoldi “ Dynamic Routing for Flying Ad-Hoc Networks (FANETs): A survey," Ad Hoc Networks, vol. 11, no. 3, pp. 1254-1270, 17 June 2014.

10. I. Bekmezci, O. Sahingoz, Ş Temel,"Flying ad-hoc networks (FANETs): A survey." Ad Hoc Networks 11. No 3 1254-1270,2013.

11. O. KSahingoz. "Routing ptocols in flying Ad-hoc networks (FANETs): Concepts and challenges". Journal of Intelligent \& Robotic Systems, pp. 513-27.April 2014.

12. Ozgur, Koray and Sahingoz, "Networking Models in Flying Ad-Hoc Networks (FANETs): Concepts and Challenges", Springer Science, September,2013. 


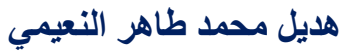 \\ جامعة الانبار - العراق مداق
}

المستخلص : (المص

الثبكات الجوية المخصصة (FANET) هي عبارة عن مجموعة من المركبات الجوية بدون طيار (الطائرات

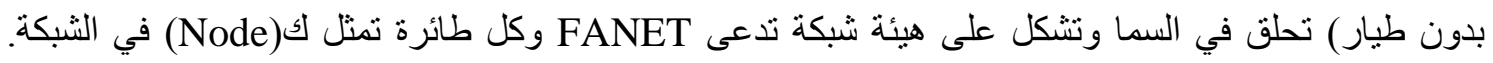

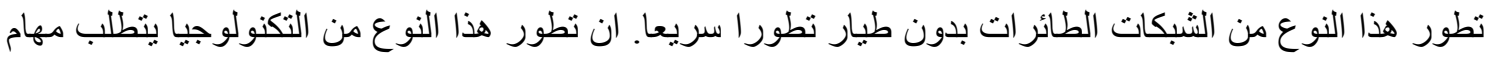

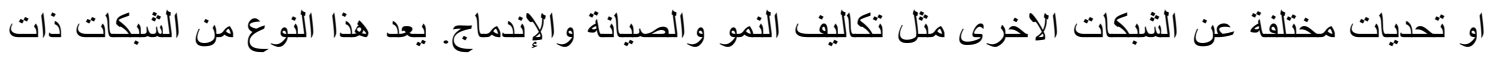

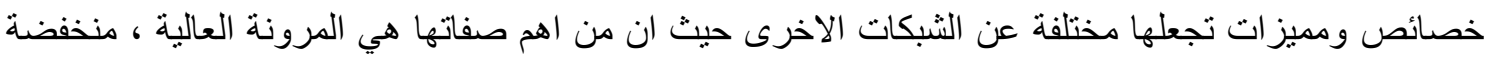

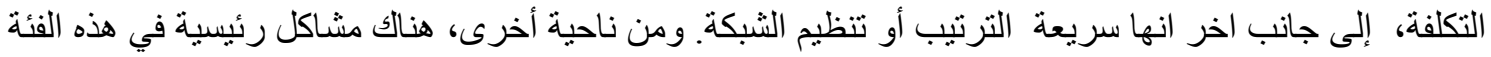

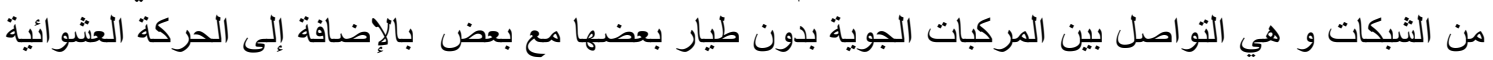

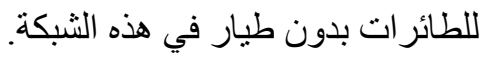

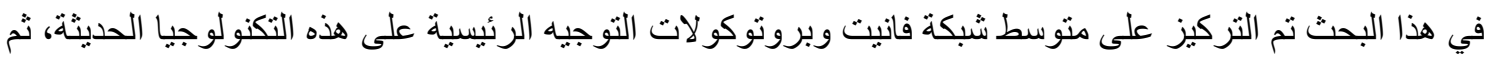

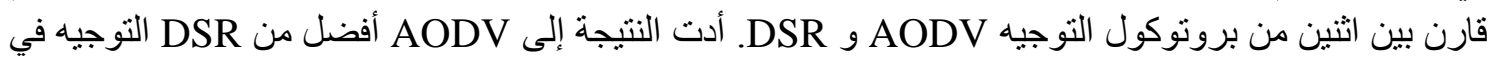
ثلاث من اهم المقاييس الاساسية في الثبكات وهي : E2E ، PDR التأخير و الإنتاجية(Throughput). إلى ذللك AODV أكثر ملاءمة لبيئة فانيت من DSR مع عدد مختلف من العقد (Nodes) في شبكة فانيت. 